This item was submitted to Loughborough's Research Repository by the author.

Items in Figshare are protected by copyright, with all rights reserved, unless otherwise indicated.

\title{
Design and development of a classification system for knowledge management tools and methods
}

\section{PLEASE CITE THE PUBLISHED VERSION}

\section{PUBLISHER}

Professional Engineering Publishing / @ IMechE

\section{VERSION}

VoR (Version of Record)

\section{LICENCE}

CC BY-NC-ND 4.0

\section{REPOSITORY RECORD}

Barnett, Timothy J., Jennifer A. Harding, and A. Nurse. 2019. "Design and Development of a Classification System for Knowledge Management Tools and Methods". figshare. https://hdl.handle.net/2134/6462. 
This item was submitted to Loughborough's Institutional Repository (https://dspace.lboro.ac.uk/) by the author and is made available under the following Creative Commons Licence conditions.

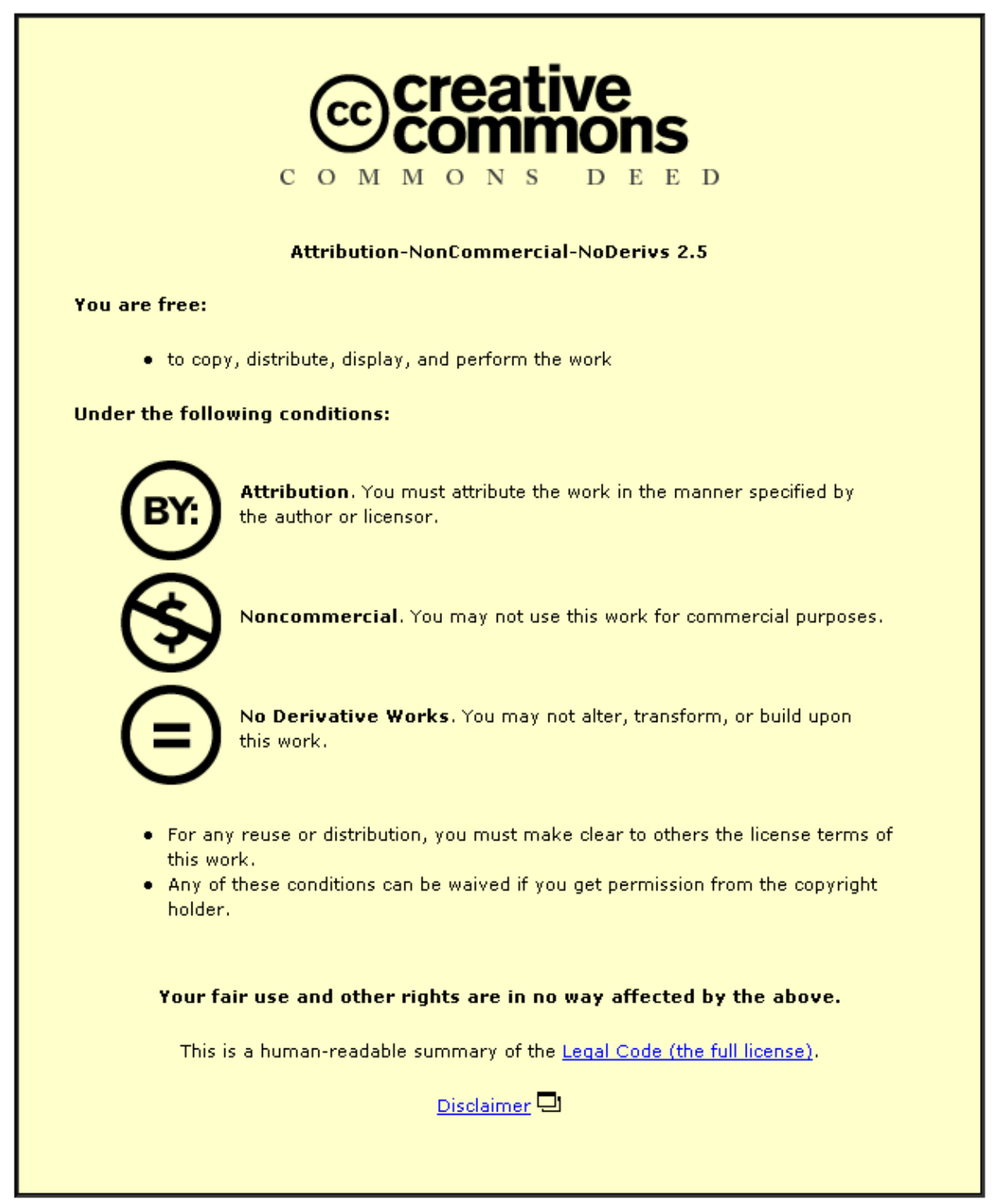

For the full text of this licence, please go to: http://creativecommons.org/licenses/by-nc-nd/2.5/ 


\title{
Design and development of a classification system for knowledge management tools and methods
}

T J Barnett, J A Harding*, and A Nurse

Wolfson School of Mechanical and Manufacturing Engineering, Loughborough University, Loughborough, UK

The manuscript was received on 31 March 2009 and was accepted after revision for publication on 19 October 2009.

DOI: 10.1243/09544054JEM1582

\begin{abstract}
Mechanical and manufacturing engineering (MME) organizations commonly recognize the value of their knowledge resources, yet most fail effectively to exploit these assets. Knowledge management (KM) solutions should provide the means for appropriate exploitation of the resources, but there are very few published KM implementations in MME contexts compared with the wealth of KM solutions published in other sectors. This paper demonstrates a methodology for the creation of a KM solution space based on the review, analysis, and characterization of 157 sources, including examples of KM problems within 55 companies from 16 different industry sectors. The example KM solution set can be used to identify appropriate tools to solve KM-related problems in many MME contexts.
\end{abstract}

Keywords: knowledge management, solution space, knowledge management solutions, KM, $\mathrm{KM}$ resources, KM best practice, knowledge management resources, knowledge management best practice, KM process, KM tools

\section{INTRODUCTION}

It is widely accepted that engineering research, design, and development and manufacturing processes are highly reliant upon the valuable knowledge, experiences, and skills stored within the companies' systems, processes, documents, and employees $[\mathbf{1}, 2]$. With an ageing population, a highly mobile and dispersed workforce, and compressed development times across all engineering industries, the effective management and exploitation of these knowledge, experience, and skills 'resources' are critical the factors to success in both developing and subsequently sustaining competitiveness. Indeed, it is apparent in some cases that the very survival of the business can be reliant upon the manner in which these key knowledge and experience resources are treated [2]. If key knowledge resources can be identified, maintained, and efficiently controlled, prior successes and failures can be capitalized upon, best practices can be captured and transferred, and

*Corresponding author: Wolfson School of Mechanical and Manufacturing Engineering, Loughborough University, Ashby Road, Loughborough, Leicestershire LE11 3TU, UK.

email: j.a.harding@lboro.ac.uk new solutions can be developed with minimal duplication of effort and without unnecessary replication of prior work.

Away from manufacturing and engineering organizations, in the broader business world, an array of solutions exists, consisting of tools and techniques developed specifically to facilitate the management of knowledge and experience. These solutions have achieved widespread recognition for their capabilities and consequent importance in enhancing business processes across a variety of business applications and contexts. However, their relevancy, applicability, and relative merits in particular manufacturing or mechanical engineering contexts are generally not clear.

Initially, the non-specific and broad nature of terms such as 'knowledge management' (KM) can imply a 'fix all' generic tool or technique. Further investigation, however, quickly uncovers a myriad of extremely diverse, context-specific, and highly customizable solutions that are often implemented and adapted locally. It can therefore be a daunting challenge for a company to identify effective and efficient KM solutions to meet its requirements appropriately. The research presented in this paper addresses this challenge through the development of a new holistic solution space via extensive 
review and analysis of the literature identifying existing KM solutions discussed and implemented across a broad range of industries.

It is evident that engineering organizations recognize and accept the value of and consequences associated with their key knowledge and experience resources when it is brought to their attention, yet most have failed effectively to exploit the available value and benefits [3]. The research presented here is based on the belief that existing tools and solutions that have been developed and implemented to manage knowledge and experience in the wider business world should also be valuable within manufacturing and mechanical engineering organizations to enhance the utilization, management, control, and protection of identified key 'resources' critical to the success of engineering processes. However, they should be made suitable, relevant, concise, and accessible to maximize the benefits gained from the potential that they offer.

\section{KM AND MECHANICAL AND MANUFACTURING ENGINEERING}

Common needs and requirements within mechanical and manufacturing engineering (MME) areas have been identified and discussed in various research projects. These are summarized from the literature as follows $[\mathbf{1}]-[\mathbf{4}]$ :

(a) sharing and transferring findings and knowledge for future use;

(b) understanding reasons for and results from previous work and decisions;

(c) managing increase in product knowledge associated with huge increase in product complexity;

(d) reduced timescales and increasing competition;

(e) increasing personnel turnover rates and a more fluid workforce (traditionally, engineering was perceived as a job for life).

By reviewing the key drivers and benefits from $\mathrm{KM}$ implementations in a wide range of contexts, it becomes clear that these correlate well with the requirements listed above. However, the literature presents only isolated incidences of KM implementations in the MME fields while offering a wealth of implementations away from such sectors. A review of the literature covering a wide range of industries finds a plethora of KM solutions, tools, and systems, providing a diverse range of KM implementations, models, tools, and solutions either proposed or exemplified via adoption within organizations. Several authors refer to a spectrum of $\mathrm{KM}$ tools from which to select solutions. These spectra often contain a narrow selection of tools specific to their industry, sector, or experiences. The quantity and flexibility of reported KM solutions and implementations potentially provide industry with powerful solutions to meet its KM challenges; however, the literature provides very little guidance on how to identify and implement appropriate KM solutions for particular companies or circumstances. The research reported here aims to narrow that gap.

This research seeks to exploit and assist the exploitation (where possible and appropriate) of existing solutions from the wider business world to provide new opportunities within MME sectors. Additionally, it provides a mechanism for exploiting existing inter-sector research and facilitating its uptake in MME fields promoting 'crossfertilization' and inter-sector learning. To achieve this, a substantial number of existing KM sources and KM implementations have been reviewed. They have been analysed and their features and details and have been summarized into generic formats or against developed criteria to satisfy the appropriate objectives. Many types of KM reference have been examined including management publications, academic journal papers, trade material, conference proceedings, and personal contacts, and a structured analysis has been carried out of each of these reviews (to identify common themes and distinct differences). This enabled the creation of summary statements, frameworks, or structures based on the content of the reviewed materials. The results of this detailed review indicated that the plethora of available KM solutions, tools, and techniques can be systematically processed to produce a holistic solution space to assist practitioners in MME contexts to select the most appropriate tool (or group of tools) to satisfy their KM requirements. The output from this research is referred to and considered to be a 'KM solution space'. Fundamentally, this solution space is composed of a classification system/taxonomy populated with a plethora of live and previously used KM tools that can then be applied as a problem-solving tool because the KM tools are classified according to the type of problem they can solve and types of improvement they can influence. The solution space will facilitate improvements within MME organizations by fulfilling the function of a KM toolbox (including instructions as to how to determine which tool to use and then subsequently how to use it). The methodology for developing the solution space is discussed in section 3 . 


\section{METHODOLOGY FOR CREATION OF KM SOLUTION SPACE}

The methodology adopted in this research is analogous to Blessing's (Blessing 95) design research methodology [5]. The key principles and concerns were to ensure an initial robust review identifying all of the relevant literature (including company sources, conferences, and trade literature, since the practical and industrial nature of the KM solutions means that not all KM instances appear in typical academic publications) and a subsequent rigorous analysis of the identified sources to fulfil the appropriate objectives. This was achieved by:

(a) a clearly defined problem (objectives to fulfil were identified for each element of the research; see stages 1 to 8 in Fig. 1);

(b) prescribing a solution (including the review and analysis of appropriate criteria, scope, and sources to fulfil these objectives);

(c) evaluating how the problem is fulfilled (i.e. via satisfaction of objectives) by subsequent quantitative and qualitative analysis.

Having reviewed and collated instances and details of KM usage it was critical that the KM solution space should have a sufficiently detailed, flexible, valid, and broad classification structure in which these solutions could be placed. In order to fulfil this, a taxonomy development methodology analogous to that presented by Breininger et al. [6] was employed.

A robust methodology was essential to deliver this element of the solution space owing to a number of interrelated factors, including a diverse range of sources. Owing to the rate of adoption and organic development of KM tools and systems over the last 20 + years, numerous KM classification systems and taxonomies have been developed to explain the detailed use of certain products in an application, how specific industries or customers understand tools use, and to represent the current 'KM tool-set' at a certain point in time. This has produced some extremely focused categorization sets that are very specific to a certain subset of tools or a certain industry and lead to a range of entwined and overlapping classifications that do not provide a clear view of the entire KM tool landscape.

Tables 3 and 4 (see later) cover a sample of the classification systems and taxonomies identified from the literature. In summary these existing classification systems had been developed around specific areas of KM (e.g. industry focused (Law) or solution-focused (purely IT-based solutions)) and there was not a single 'range' apparent that covered the whole diverse spread of KM solutions identified through the review.

In order to deliver a holistic classification system, the key elements of the reviewed systems were adapted, enhanced, and combined to ensure that they could accurately cover all of the specific identified and generic types of KM solution, thus enabling categorization of current solutions while being sufficiently broad, flexible, and robust to provide a 'future-proof' solution as new KM tools and techniques are developed.

Figure 1 presents the methodology, scope of the reviews, and distinct research area elements. Each stage (1-8) of the methodology is now discussed in detail.

\subsection{Drivers and reasons (stages 1 and 2)}

The selection and implementation of KM solutions represents a significant challenge and change for most organizations; therefore, it is important to determine the drivers and benefits associated with implementing KM solutions. A review was therefore carried out to identify and summarize these and to provide an overview of the requirements, success factors, problems, and issues associated with such implementations. The three core objectives of this wide-ranging review were as follows.

1. Identify the core drivers and reasons for using KM as presented, discussed, and developed in the literature.

2. Identify the core reported drivers and reasons for specific organizations implementing KM.

3. Produce a succinct summary of drivers and motivations for KM implementations as ascertained from the literature and published company information.

The review indicated that there is significant evidence of a broad range of drivers for implementing KM within an organization. Looking at 28 companies' reasons for implementations led to the identification of 20 key requirements in seven key sections: these are presented in Table 1. There also appears to be a set of five core driver elements that are frequently cited across publications and organizations; these are presented in Table 2.

\subsection{Review: models and classification (stages 3 and 4)}

In stages 3 and 4 , a review was carried out of the multitude of KM models and systems in the published literature on KM practices and processes, to characterize their core features and compare their similarities. The literature presented aimed to satisfy the following objectives. 
1. Identify, review, compare, and summarize the different KM processes, models, and methodologies presented in the literature.

2. Identify, review, compare, and summarize the different classifications and categories for KM solutions/tools as presented in the literature.
Many commonalities and differences can be identified within KM processes. This is partly because authors use varying terminology and processes have often been developed within organizations for specific contexts. However, from the ten processes identified in this review it is clear that the functions and subprocesses

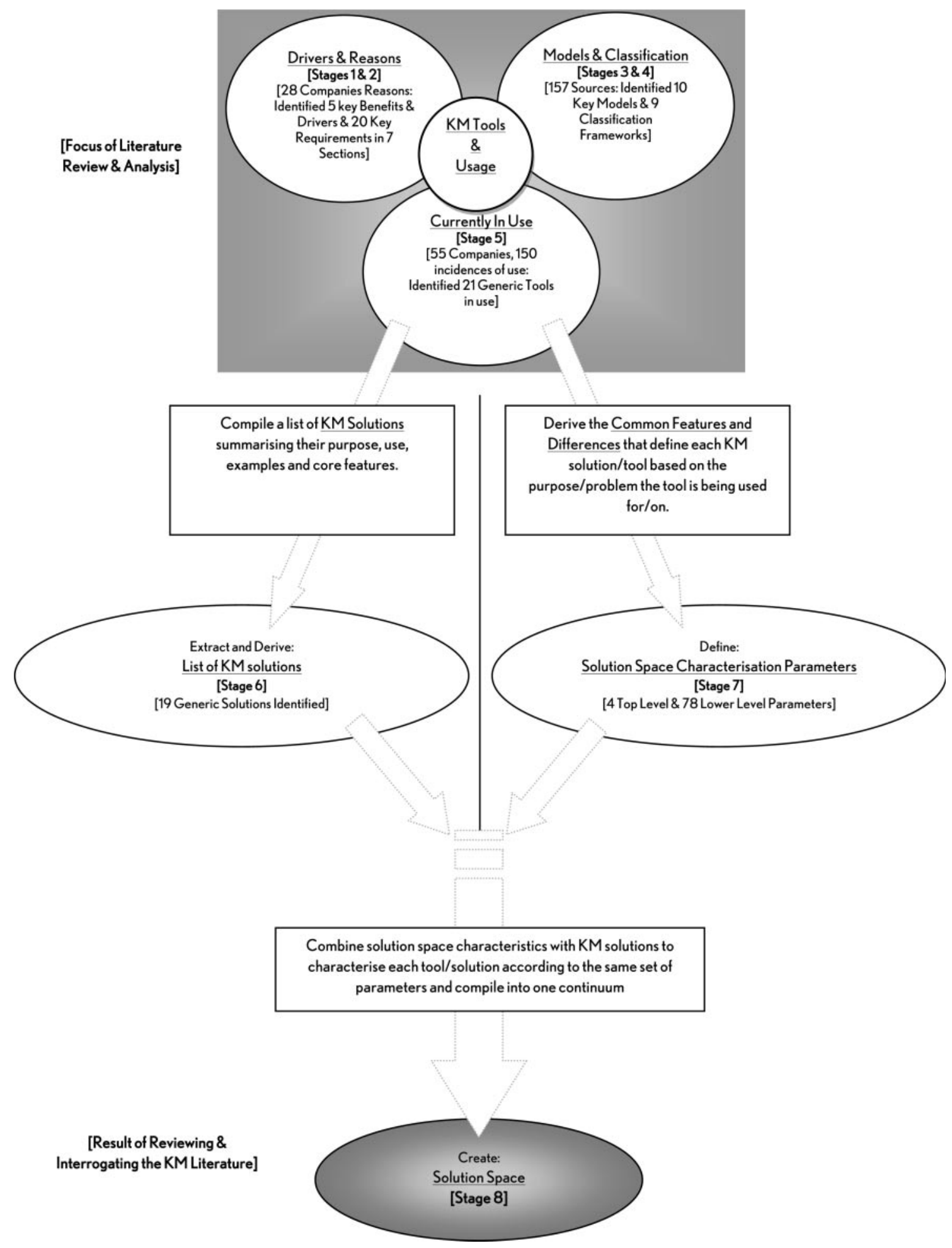

Fig. 1 Research process 
Table 1 Summary of KM Requirements, success factors, problems and issues from the literature

\section{Goals and objectives:}

- Clearly align the KM initiative to the business goals.

- Involve personnel and ensure that the plan and strategy are clearly communicated.

- Define measurable objectives for implementations.

Culture:

- Understand how knowledge fits into the current culture, particularly the organisation option on sharing knowledge and collaboration internally and externally. The culture should value knowledge creation and knowledge sharing.

- Understand how knowledge is currently transferred within the organization and how it could be, i.e. analyse the lines of communication.

- Understand any history relating to change or previous KM implementations within the company - these can have serious effects on future implementations.

- Understand and, if necessary, implement reward and recognition systems and schemes that reward sharing of knowledge and collaborative working; individual-based rewards can hinder knowledge sharing and ultimately prevent KM initiatives.

- KM requires a common ground among people, the organization culture should value the knowledge held in their employees heads and give them reasons to share the knowledge.

Technology:

- IT can complement and facilitate the implementation but is rarely the key or sole solution to KM problems.

- IT KM solutions must complement and fit in or ideally utilize existing IT and technology systems wherever possible.

- Benefits of face-to-face contact are rarely provided by technology and should not be forgotten.

Integration:

- Integrate and embed the KM tools into existing business functions.

- Couple the KM implementations with another business activity.

\section{Implementation:}

- Top-level commitment for the KM project is important and a well-selected and influential steering committee is needed.

- Support should be from all levels of the organization, ideally via informal champions at each level of the organization.

- Dependent upon organization type, it may be most appropriate to implement early KM initiatives 'under the radar' becoming visible when established and proven successful.

Location and structure:

- Locate the KM initiative close to the business front end where the effect can be seen.

- The KM initiative should have the aim of becoming fully integrated into the business processes over the long term with the KM solution embedded into the work flow so that knowledge can be captured, shared, and reused as part of day-to-day work.

- Consider the physical business structure and how this will influence the KM initiative.

Organization:

- Chosen KM solutions must be matched to what is needed within the organization while considering what has been done before and the capabilities of the organization and its employees. It is essential that the chosen solutions are appropriate to the problem being solved and the organization.

Table 2 Summary of benefits and drivers of KM identified.

- Share, transfer, and capture knowledge, findings and experience from across entire organizations to ease and facilitate future use and concurrently to reduce the opportunity for unnecessary repetition of tasks.

- Provide a mechanism to access different pools of knowledge internally and externally and to provide appropriate tools to leverage these.

- Increase employee effectiveness, and manage and track employee competencies within a distributed more fluid and ageing workforce.

- Reduce time-to-market and improve reaction to market changes, reduce risk by using more mature solutions.

- Provide a driver for the innovation process by creation, distribution and discussion of new ideas.

identified can be divided into four appropriate 'toplevel' categories relating to the need for processes to capture, transfer, create, and locate knowledge.

1. Objective (1) was satisfied by identifying and comparing a spectrum of KM implementations from 157 referenced sources, 55 companies, and 16 industry sectors. This led to ten distinct models being identified by comparing and contrasting the sources (Table 3 ).
2. Objective (2) was satisfied since the review of KM classifications, categorizations, and frameworks revealed relevant research from nine authors ranging from complete spectrums of categories to categories for specific groups of tools (i.e. knowledge transfer, as shown in Table 4).

\subsection{Review: currently in use (stage 5)}

Considering the aim of this research to develop a solution space containing existing KM solutions, an extensive literature and company review was conducted to determine which tools are available and the circumstances of their use.

KM implementations across a broad range of industries and businesses were studied, examining 16 industry sectors, 150 incidences, and 55 companies, focusing on specific tools and suggested or implemented solutions. Analysis of this literature resulted in the identification of 21 generic types of tool and these are summarized, with details of the organizations which have applied them, in Table 5. 


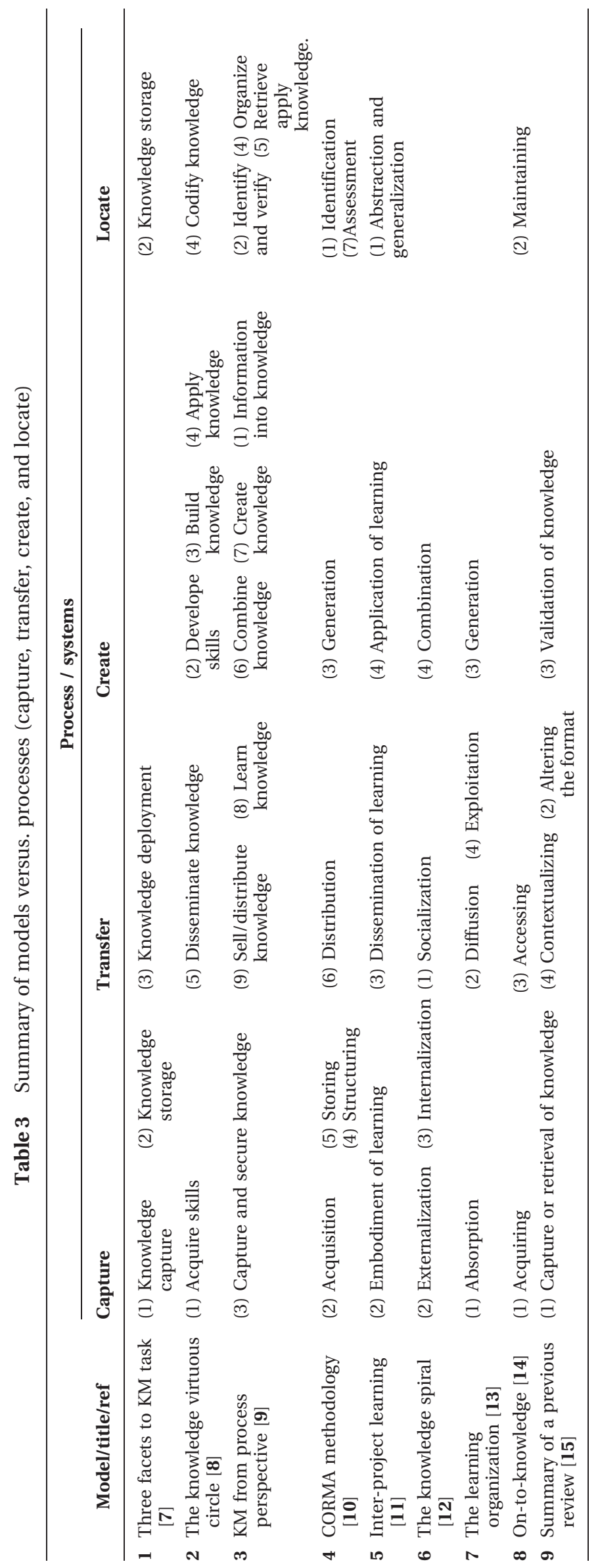


Table 4 Summary of classification categories identified from the literature

\begin{tabular}{|c|c|c|}
\hline Functions/area & Categories & Reference \\
\hline \multirow{4}{*}{$\begin{array}{l}\text { The approach } \\
\text { taken }\end{array}$} & - Hard versus soft approaches. & {$[16]$} \\
\hline & - Codification versus personalization. & {$[17,18]$} \\
\hline & $\begin{array}{l}\text { Two core elements: knowledge acquisition processes and } \\
\text { knowledge representation technology. }\end{array}$ & {$[17]$} \\
\hline & $\begin{array}{l}\text { Three tier KM system: presentation services, knowledge } \\
\text { services, infrastructure services. }\end{array}$ & [19] \\
\hline \multirow{3}{*}{$\begin{array}{l}\text { The KM } \\
\text { processes } \\
\text { involved }\end{array}$} & $\begin{array}{l}\text { Three-tier KM model: communication, resource layer, } \\
\text { process layer. }\end{array}$ & {$[20]$} \\
\hline & $\begin{array}{l}\text { Nine core aspects to KM: content, portal, collaboration, learning, } \\
\text { social capital, expertise, business intelligence, business } \\
\text { integration. }\end{array}$ & {$[21]$} \\
\hline & $\begin{array}{l}\text { KM spectrum: transactional, analytical, asset management, } \\
\text { process, developmental, innovation and creation. }\end{array}$ & {$[22]$} \\
\hline \multirow{2}{*}{$\begin{array}{l}\text { Dissemination } \\
\text { and transfer } \\
\text { processes }\end{array}$} & $\begin{array}{l}\text { Five types of transfer: serial transfer, near transfer in team, } \\
\text { near transfer, far transfer, strategic transfer. }\end{array}$ & [23] \\
\hline & - Two transfer mechanisms: push versus pull. & {$[21]$} \\
\hline
\end{tabular}

\subsection{Compile and derive: extract and derive a list of KM tools and solutions (stage 6)}

In order to develop a single-solution space for the KM solutions and allow comparison, it was first necessary to summarize each KM solution (Table 5) and then present them in the same format. Love et al. [17] stated that, considering the unique nature of valuable (knowledge) resources within individual companies, it should not come as a surprise that firm-specific KM systems will develop. From initial reviews this may appear to be the case; however, on closer scrutiny and by considering the features and roles of the different tools and solutions it becomes clear that many of the tools and solutions, are fundamentally the same, varying only in the terminology used to describe them and the specifics of the resources and contexts within which they are used. Examples of this include:

(a) communities of practice: also known as communities of interest, knowledge-sharing communities, and forums, although on close inspection it is apparent that each solution is fundamentally the same.

(b) competency management: customized and known by different names by various organizations (Yellow Pages, Expertise Directories, Expert Networks (internal) ); however, when reviewed, each tool is actually providing the same solution. The consolidated generic tools and solutions list are presented in Table 6 .

\subsection{Compile and derive: solution space characterization parameters (stage 7)}

The combined results from stages 1 through to 6 provide the essential components of a KM solution space. Extensive manual analysis of the KM tools and solutions reported in Table 5 was conducted by first identifying and then comparing their key characteristics to identify differences and similarities. This led to the identification of 19 distinct KM solutions; these are presented in Table 6.

The findings were then utilized to develop a set of 'characterization parameters' to enable the categorization of a KM tool based on the problem or issue that the tool is to be used to address. The characterization parameters were determined by considering previous parameters that have been defined by authors (stages 3 and 4) and the scope, application, and features of the KM tools and implementations detailed. Reviewing and analysing the classifications schemes (nine identified in Table 4) and generic KM solutions (19 identified in Table 6), four top-level and 78 lower-level characteristics were identified by analysing the characteristics of the solutions; it was clear that:

(a) KM implementations cover a plethora of tools and solutions;

(b) there are similarities in solutions used across different industries;

(c) the use and success of individual KM solutions are strongly dependent upon the circumstances and context.

From the surveyed implementations and the summarized solutions illustrated, the following statements can be made; each KM solution will be associated with at least one of the following core actions:

(a) capture - knowledge and experience from people, process, documents, and findings;

(b) create - create solutions using knowledge and experience;

(c) locate - knowledge and experience;

(d) transfer - knowledge and experience. 
Table 521 distinct KM tools identified by analysis and comparison of the implementations

\begin{tabular}{|c|c|}
\hline KM tools and solutions & Organizations using tools and solutions (150 incidences of use) \\
\hline $\begin{array}{l}\text { Best-practice capture and } \\
\text { reuse systems }\end{array}$ & $\begin{array}{l}\text { Ford Motor Company }[\mathbf{1 6}, \mathbf{2 4}] \text {, Texas instrument[21], Ericsson Global Services }[\mathbf{2 5}] \text {, Chevron }[\mathbf{1 2}, \mathbf{2 6}] \text {, BAE } \\
{[\mathbf{2 7}] \text {, Airbus }[\mathbf{2 8}, \mathbf{2 9}] \text {, Outokumppu Finland }[\mathbf{1 6}] \text {, Caterpillar }[\mathbf{3 0}]}\end{array}$ \\
\hline Best-practice design guides & Chevron $[\mathbf{1 2}, \mathbf{2 6}]$, Tennessee Valley Authority [23], Xerox- [31] \\
\hline $\begin{array}{l}\text { Capturing best practices } \\
\text { via video }\end{array}$ & Intel [32], NASA [33], Pratt and Whitney Rocketdyne [34], British Petroleum [12, 35] \\
\hline Communities of practice & $\begin{array}{l}\text { BAE [27], Belron (Ratioone) and (Microsoft) [36], British Petroleum }[\mathbf{1 2}, \mathbf{3 5}] \text {, Caterpillar }[\mathbf{3 0}] \text {, Chevron }[\mathbf{1 2} \text {, } \\
\text { 26], Ernst \& Young [26], Frito-Lay [26], Mckinsey [8, 16], Rolls-Royce [37], Siemens medical [38], Ericsson } \\
\text { Global Services [25], Federal Aviation Administration (FAA) [33], Ford Motor Company }[\mathbf{1 6}, \mathbf{2 4}]\end{array}$ \\
\hline Competency management & $\begin{array}{l}\text { Ernst \& Young [26], Microsoft (Microsoft), Pfizer Switzerland [16], Pratt and Whitney Rocketdyne [34], } \\
\text { United Technologies [26], Rolls-Royce [37], NASA [33], Siemens Medical [38], Caterpillar [30], Oticon } \\
\text { Denmark [19] }\end{array}$ \\
\hline $\begin{array}{l}\text { Content management and } \\
\text { engineering }\end{array}$ & $\begin{array}{l}\text { Pratt and Whitney Rocketdyne }[\mathbf{3 4}] \text {, Boeing }[\mathbf{1 6}, \mathbf{3 9}] \text {, Genera Electric (GE) Research }[\mathbf{4 0}] \text {, Mckinsey }[\mathbf{8}, \mathbf{1 6}] \text {, } \\
\text { DOW Chemicals }[\mathbf{1 6}] \text {, Frito-Lay }[\mathbf{2 6}] \text {, National Bicycle Company }[\mathbf{1 6}] \text {, Nokia }[\mathbf{4 1}] \text {, PLS-Consult Sveiby }[\mathbf{1 6}] \text {, } \\
\text { Sony }[\mathbf{4 2}] \text {, Xerox- }[\mathbf{3 1}] \text {, Ernst \& Young }[\mathbf{2 6}] \text {, Recruitment consultants }[\mathbf{1 7}] \text {, Belron }[\mathbf{3 6}] \text {, Airbus }[\mathbf{2 8}, \mathbf{2 9}] \text {, } \\
\text { Ericsson Global Services }[\mathbf{2 5}] \text {, Research community }\end{array}$ \\
\hline $\begin{array}{l}\text { Expert networks, external } \\
\text { and internal }\end{array}$ & $\begin{array}{l}\text { National Bicycle Company [16], Engine Cylinder Block - non destructive testing [44], Agro Corp [16], } \\
\text { Benetton [16], PLS-Consult }[\mathbf{1 6}] \text {, Pratt and Whitney Rocketdyne }[\mathbf{3 4}] \text {, Mckinsey [8, 16], Netscape }[\mathbf{1 6}]\end{array}$ \\
\hline Forums & $\begin{array}{l}\text { Hewlett Packard }[\mathbf{1 6}, \mathbf{2 6}] \text {, Fulcrum Pharma [43], Pratt and Whitney Rocketdyne [34], BAE [27], NASA [33], } \\
\text { Research community }\end{array}$ \\
\hline Knowledge audits & Celami [16], Rolls-Royce [37], Telia [16] \\
\hline $\begin{array}{l}\text { Knowledge-based } \\
\text { engineering }\end{array}$ & $\begin{array}{l}\text { Airbus [28, 29], Boeing [16, 39], Jaguar [39], Lotus [39], Pratt and Whitney Rocketdyne [34], Rolls-Royce } \\
\text { [37], Engine Cylinder Block - non destructive testing [44], FE Mesh creation [45], MIRA [46] }\end{array}$ \\
\hline Knowledge maps & Chevron $[12, \mathbf{2 6}]$ \\
\hline $\begin{array}{l}\text { Learning during an event, } \\
\text { document and experience } \\
\text { management }\end{array}$ & Clarke Chapman control systems [47], Ritz Carlton [16, 48], Northumbrian Water [25] \\
\hline $\begin{array}{l}\text { Lesson-learnt reviews/after- } \\
\text { action reviews }\end{array}$ & British Petroleum [12, 35], US Army [2, 21, 35], Rolls-Royce [37], Fulcrum Pharma [43] \\
\hline Mentoring/piggy-backing & Rolls-Royce [37], Affärsvärlden Sweden, Business journal [16], Affärsvärlden Sweden, Business journal [16] \\
\hline Peer assist & British Petroleum [12, 35], Rolls-Royce [37], Siemens Medical [38] \\
\hline Portal & $\begin{array}{l}\text { Ford Motor Company }[\mathbf{1 6}, \mathbf{2 4}] \text {, British Petroleum }[\mathbf{1 2}, \mathbf{3 5}] \text {, Airbus }[\mathbf{2 8}, \mathbf{2 9}] \text {, Hewlett Packard }[\mathbf{1 6}, \mathbf{2 6}] \text {, Airbus } \\
{[\mathbf{2 8}, \mathbf{2 9}] \text {, Ericsson Global Services }[\mathbf{2 5}] \text {, Frito-Lay }[\mathbf{2 6}] \text {, Nokia }[\mathbf{4 1}] \text {, Xerox }[\mathbf{3 1}] \text {, Pratt and Whitney }} \\
\text { Rocketdyne }[\mathbf{3 4}] \text {, Belron }[\mathbf{3 6}] \text {, Mckinsey }[\mathbf{8}, \mathbf{1 6}] \text {, Ford Motor Company }[\mathbf{1 6}, \mathbf{2 4}]\end{array}$ \\
\hline $\begin{array}{l}\text { Storytelling/facilitating } \\
\text { communication }\end{array}$ & Ely Lily [49], Intel [32], Rolls-Royce [37] \\
\hline TRIZ & Pratt and Whitney Rocketdyne [34], Rolls-Royce [37] \\
\hline Yellow pages & $\begin{array}{l}\text { British Petroleum }[\mathbf{1 2}, \mathbf{3 5}] \text {, Chevron }[\mathbf{1 2}, \mathbf{2 6}] \text {, Frito-Lay }[\mathbf{2 6}] \text {, Mckinsey }[\mathbf{8}, \mathbf{1 6}] \text {, United Technologies }[\mathbf{2 6}] \text {, } \\
\text { NASA [33], Rolls-Royce [37], Siemens medical }[\mathbf{3 8}]\end{array}$ \\
\hline
\end{tabular}

Further to this it is apparent that the solutions can be categorized according to:

(a) the type of resource or knowledge they work with or the knowledge and experience stored within:

(i) people/people's experiences;

(ii) documents;

(iii) rules/guidelines;

(b) the time within a process in which the solutions are used:

(i) before an event occurs;

(ii) during an event;

(iii) after an event has occurred; (c) the generic types of solutions:

(i) 'people based' with IT as a support;

(ii) IT based with people as support.

By considering the above categories and reviewing each of the KM solutions surveyed against them, a set of solution space categories were developed and these are best illustrated in Fig. 2.

\subsection{Create: solution space (stage 8)}

The reviews and analysis from stages 1 to 6 are used to develop a single-solution space by considering the details of where each solution is used, what it is used for, and any specific requirements it may have, the 
Table 6 Summary list of KM solutions

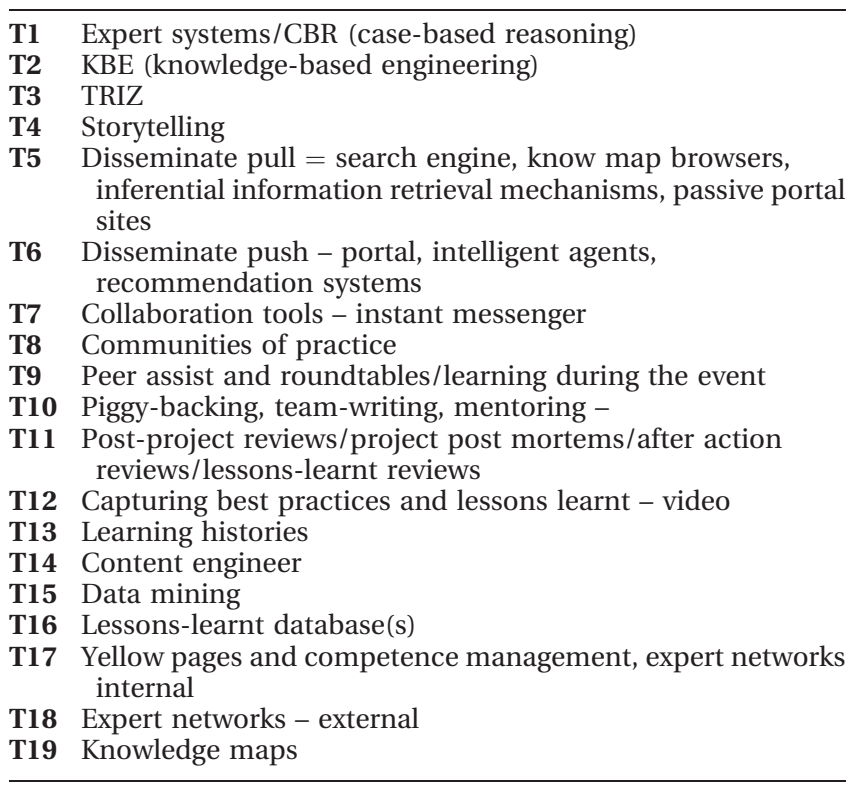

output being a single-solution space containing a list of requirements and conditions of use crossreferenced to a range of KM solutions.

Having determined the KM tool classification parameters, a solution space was created by first representing each of the identified KM tools in a homogeneous format and subsequently populating the solution space with the characteristics of each tool. This creates a profile of each KM solution and presents all the solutions in one single-solution space.

The final solution space is presented in Fig. 3.

\section{CONCLUSION AND FURTHER WORK}

An extensive and broad KM review has been completed across a diverse range of implementations and organizations. Drivers, motivators, reasons, problems, issues, benefits, and specifications of KM tools were reviewed and profiling tools were analysed against a new and unique set of characterization parameters enabling side-by-side comparison of any $\mathrm{KM}$ tool in the KM-solution space.

The completed profile features the key characteristics of each of the identified KM tools. Some key points on the solution space are outlined below.

1. In compiling the solution space the total number of solutions was significantly reduced as it became apparent that some solutions and tools presented in the literature were fundamentally the same tools with different names.

2. Each type of solution has at least one of the four primary functions: capture, create, locate, and transfer.
3. Each solution has secondary functions for which they can also be used, i.e. Storytelling's primary purpose is to transfer knowledge and experience between individuals: as part of this, knowledge is routinely captured in the new individual's head or notes made.

4. Many solutions have tertiary requirements based on things that must have happened before, i.e. a paper-based or electronic best-practice design guide is primarily for transferring key information to other people; however, the actions of creating/ writing require that the capture process must have happened or be happening.

5. There is not an equal split between the four primary functions $(8=$ locate, $6=$ capture, $4=$ create, and only 1 has a primary function of transfer). It is therefore important to consider the secondary and tertiary functions for a more rounded and accurate view of a solution's actual uses.

6. It is clear that KM can be used to tackle a broad range of problems and requirements.

Finally:

7. Given a KM/process problem statement/profile consisting of one or more of the core actions (capture/create/transfer/locate) and any further requirements (format, storage, timing, etc.), suitable solutions can be selected by matching the KM problem statement profile to the profile of tools in the solution space.

It is this final point that is the most useful and powerful outcome from creating the solution space.

At the outset of this paper it was noted that:

(a) MME organizations rely heavily on the valuable knowledge, experiences, and skills stored within the companies' systems, processes, documents, and employees;

(b) away from manufacturing and engineering organizations, in the broader business world, an array of solutions exists, consisting of tools and techniques developed specifically to facilitate the management of knowledge and experience.

The creation of the KM solution space provides a stepping-stone to allow the experience held within to be (a) tapped into and to (b) demonstrated in.

In isolation and as presented in this paper, the created solution space provides a reference of KM tools or processes that have been used to solve, satisfy, and improve KM-related problems or areas. Utilizing the solution space further, as more than an isolated reference figure, it could be further developed to be used within a process or tool with the objective of selecting and guiding the use of the most appropriate KM tool as part of a structured process 

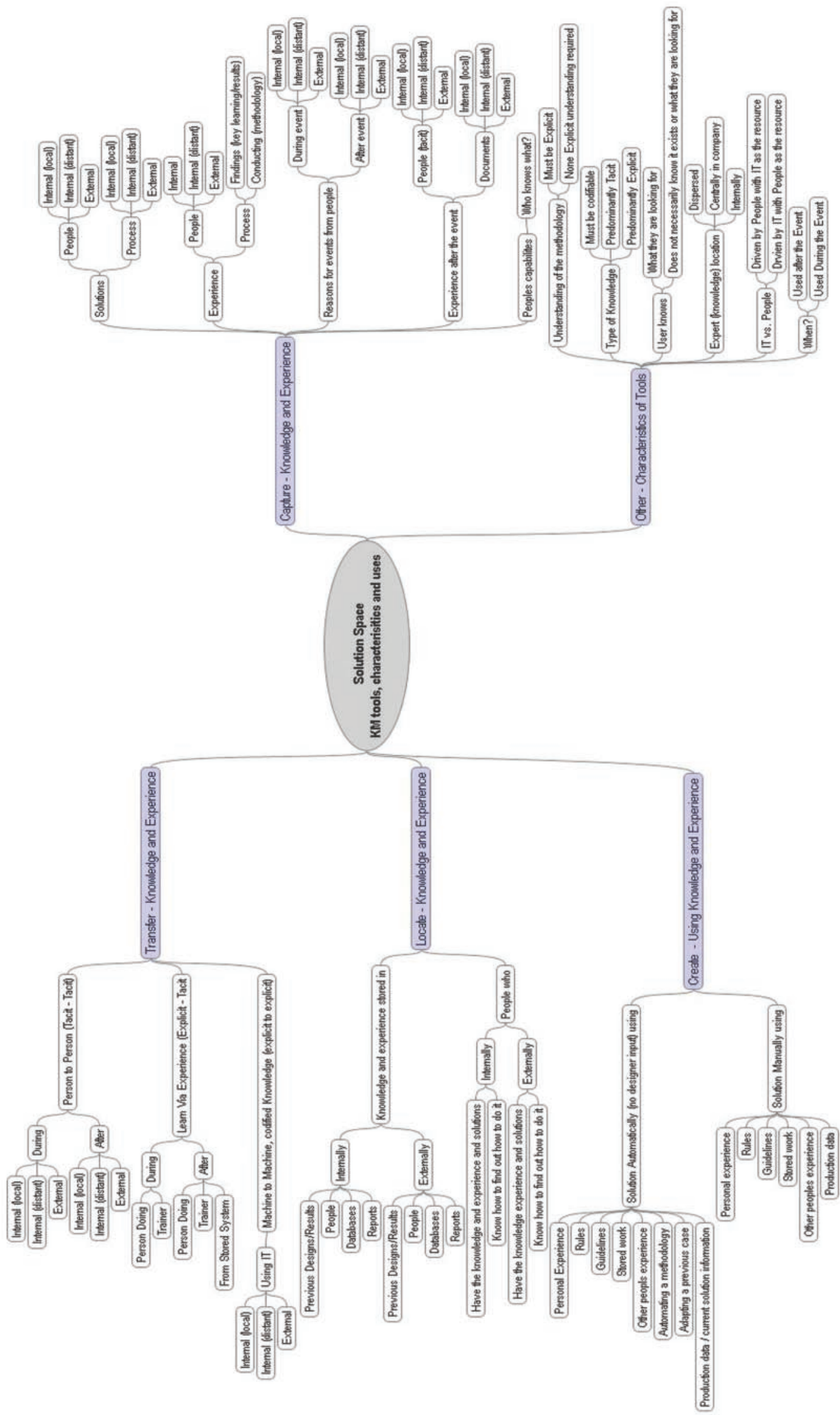

Fig. 2 Solution space category summary 


\section{A: INPUT KM Problem Statement \\ B: Matrix linking combinations of $\mathrm{KM}$ \\ Problem statements (A) to KMSolutions \\ (C) \\ C:KMSolutions}
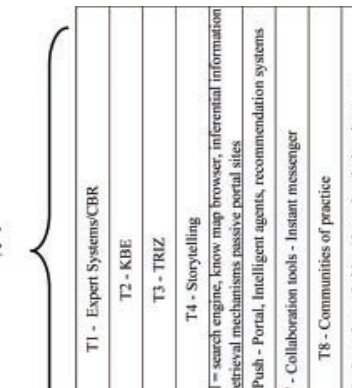

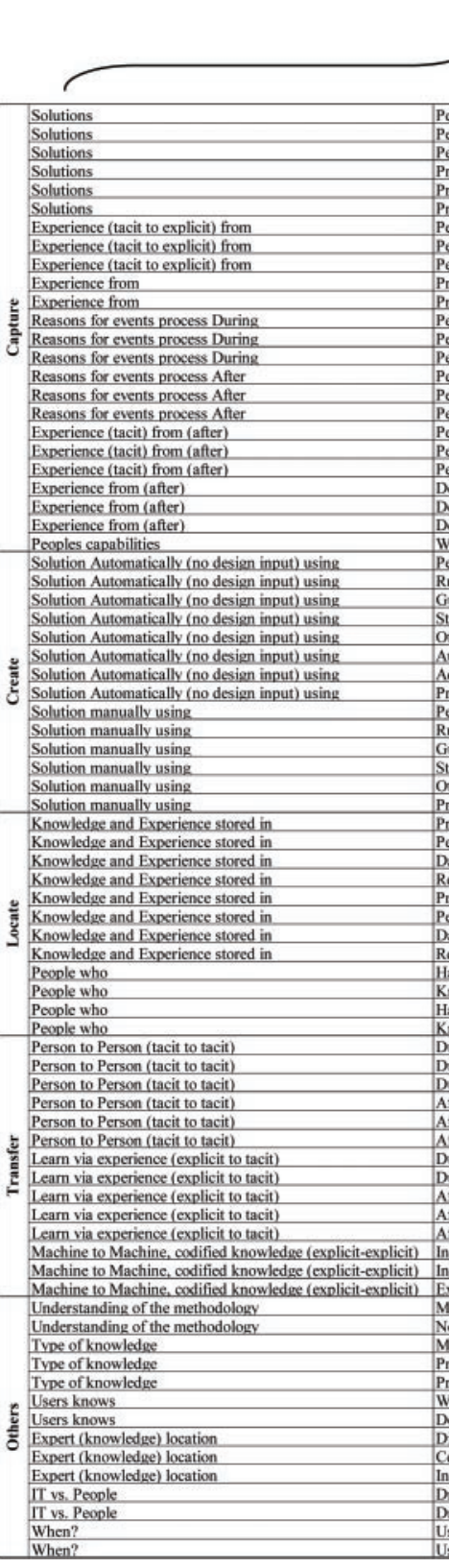

\section{A}

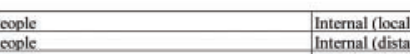

\begin{tabular}{|l|l|} 
Internal (d & External \\
\hline
\end{tabular}

Propess

Posple

Pople

Pocess

cople

Pople

People

People

People

People

Documents

Doximents

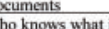

ersonal experience

ules

ared wor

Ther peoples experience

pduction data / current solution information

ersonal experiense

Gidelines

Gridelines

er peoples experience

Pevious desiens / results

seople

atabases

Pevious designs / results

Pcople

atabases

Outs

\begin{tabular}{l|l} 
Outside & Outs \\
ve the knowledge experience and solutions & Inside
\end{tabular}

\begin{tabular}{|l|l|} 
Know how to find out how to do it & Inside \\
\hline lave the knowledge experience and solutions & Outside
\end{tabular}

wow how fo find ox how to do it

Internal

\begin{tabular}{|l|l|l|l|l|l|l}
\hline Internal & Externa \\
\hline
\end{tabular}

\begin{tabular}{|l|l}
\hline After & Internal \\
\hline After & Internal (Loca \\
\hline & Persol \\
\hline
\end{tabular}

\begin{tabular}{|l|l}
\hline Internal (Lo & Exter \\
\hline ffer & External \\
\hline Persandein
\end{tabular}

Trainer

\begin{tabular}{|l|l} 
Puring & Trainer \\
\hline iler & Person doing \\
\hline & Prose \\
\hline
\end{tabular}

\begin{tabular}{l|l} 
Tenker & Trainer \\
\hline
\end{tabular}

Afernal

exe explicit understanding required

Predominantly Tacil

Prominantly Explicit

Des not necessarilv know it exists or what they are looking for

Dispersed

Centrally in company

fiven by People with IT as resourse

Driven by the IT with people to sunp

Ised after an event

sed during an event

Fig. 3 The KM solution space 
review. It is this extended and integrated use of the solution space that will be the subject of further research and publishing.

The research presented here is part of a larger project, substantial further research has been completed using this solution space, and further papers will be published covering the second and final two elements of this work, i.e. design of the KM tool and tool implementation by case study within MME organizations.

The research undertaken into the design of the KM tool will demonstrate how the developed KM tool facilitates the selection (from the solution space) and implementation of appropriate KM solutions into an engineering process via a process consisting of three stages: measurement, analysis, and solution. This process incorporates the considerations and lessons learnt from the previous implementations and considers factors specific to MME implementations when suggesting solutions.

The 'measurement' stage reviews the selected engineering process, to identify knowledge and experience resources used and resources created at each stage in the engineering process. The 'analysis and ranking' stage draws on the detail behind the KM solutions in the solution space to identify improvements and potential issues within the engineering process relating to the use and creation of knowledge and experience resources. Having identified these, the final stage, 'solve', can be applied to the areas identified for improvement and concern, as these can be formulated into a problem statement to be fulfilled. The problem statement is used as input to the solution space to select a suitable KM solution to improve the engineering process through better use of knowledge and experience created or used.

The research that has been undertaken into tool implementation includes extensive case studies, which will be used to demonstrate details of three different but typical MME processes being measured, analysed, and solved using the KM tool.

\section{(c) Authors 2010}

\section{REFERENCES}

1 Rothe, A. D. Enabling knowledge creation: Learning from an R\&D organisation. J. Knowledge Mgmt, 2003, 7 (1), 32-48.

2 Wright, B. T., Rockwell Collins, and Cedar Rapids. Ties among knowledge management, engineering practice in industry, and engineering education. IUGREEE GEAE, 1999.

3 Barnard, Y. The search for user needs. Workshop KM in engineering, from Workshop in Brussels, June 2002, EURISCO.
4 Francisco, M., del-Rey-Chamorro, R. R., van Wegen, B., and Steele, A. A framework to create key performance indicators for knowledge management solutions. J. Knowledge Mgmt, 2003, 7(1), 46-62.

5 Blessing, L. T. M., Chakrabarti, A., and Wallace, K. M. A design research methodology. In Proceedings of the International Conference on Engineering Design (ICED) 95, Prague, Czech Republic, 1995, pp. 502-507.

6 Breininger, K. and Whittaker, M. Taxonomy development process. The Internet Conference and Exhibition for Librarians and Information Managers, Monterey, California, 2007.

7 Preece, A. Better knowledge management through knowledge engineering. IEEE Intell. Systems, 2001, 1094-7167, 35-43.

8 Behin, D. Knowledge Management @ McKinsey. The Strategic Knowledge Management Forum, London, Osney Media, 2005.

9 Liebowitz, J. Knowledge-based/expert systems technology in life support systems. Kybernotes 1997, 26(5), $555-573$.

10 Wunram, M. CORMA - IST Project No. 1999-12685, 2000 (The CORMA Consortium).

11 Shapiro, G. Inter-project knowledge capture and transfer: an overview of definitions tools and practices. CoPS Innovation Centre Working paper no. 62, Brighton, 1999.

12 Rumizen, M. C. The complete idiots guide to knowledge management, 2002 (CWL Publishing Enterprises for Penguin Group).

13 Ten Have, S., Have, W., Stevens, F., and Elst, M. Key management models, 2003 (Pearson Education Limited, London).

14 Studer, R., Fensel, D., and Staab, S. Situation and perspective of knowledge engineering, 2000 (Knowledge Engineering and Agent Technology, IOS Press).

15 Coombs, R. Knowledge management practices and path-dependencies in innovation. Res. Policy, 1997, 27, 237-253.

16 Sveiby, K. What is knowledge management, 2001, available from www.sveiby.com/articles/knowledgemanagement. html (access date September 2004).

17 Love, P. E., Edwards, D. J., and Irani, Z. Management of knowledge in project environments, 2007, ch. 7 (Elsevier).

18 Dingsoyr, T. Knowledge management in medium-sized software consulting companies. Empirical Software Engng, 2002, 7, 383-386.

19 Chua, A. Knowledge management system architecture: a bridge between consultants and technologists. Int. J. Inf. Mgmt, 2004, 24, 87-98.

20 Hameri, A. WWW-enabled knowledge management for distributed engineering projects. Computers in Ind., 2003, 50, 165-177.

21 Satyadas, A. and Cassaigne, N. P. Knowledge management tutorial: an editorial overview. IEEE Trans. Systems, Man, and Cybernetics - Part C: Applic. Rev., 2001, 31(4), 429-438.

22 Binney, D. The knowledge management spectrum understanding the KM spectrum. J. Knowledge Mgmt, 2001, 5(1), 33-42. 
23 Dixon, N. M. Common knowledge: how companies thrive by sharing what they know, 2000 (Harvard Business School Press).

24 Kwiecie, S. and Wolford, D. Gaining real value through best-practice replication. Knowledge Mgmt Rev., 2001, 4 (1), 12-15.

25 Guldstrand, A. Managing knowledge for better performance. The Strategic Knowledge Management Forum, London, Osney Media, 2005.

26 Lindvall, M. and Sinha, S S. Software systems support for knowledge management. J. Knowledge Mgmt, 2003, 7(5), 137-150.

27 West, R. [BAE] Building technology around the needs of your people The Strategic Knowledge Management Forum, Osney Media, London, 2005.

28 Peltier, R. Airbus knowledge management operating model. In Proceedings of the Second International Conference on Web information systems engineering (WISE' 01), WISE Society and Kyoto University, Japan, Vol. 1, 3-6 December 2001.

29 Dotter, M. KM in engineering present and future panel discussion impulse presentation. KM in Engineering, European Commission Brussels. 21 June 2002.

30 APQC. Measuring knowledge management efforts at caterpillar, available from http://www.apqc.org/portal/ apqc/ (accessed September 2004).

31 Fischer, G. Knowledge management: problems, promises, realities, and challenges. IEEE Intell. Systems, 2001, 16(1), 60-73.

32 Intel. A new format for capturing knowledge. Intel Information White Paper, 2002, available from http://cache-www.intel.com/cd/00/00/10/28/102858_ pp023704_sum.pdf.

33 Liebowitz, J. A look at NASA Goddard Space Flight Centres knowledge management initiatives. Computing Trends/IEEE Software, 2002, 19(3), p. 40.

34 Sohn, K. D. [Rocketdyne] Building trust as a knowledge sharing foundation. The Strategic Knowledge Management Forum, Osney Media, London, 2005.

35 Parcell, C. C. G. Learning to fly, 2001 (Wiley, New York).

36 RatioOne. Microsoft Office system customer solution case study - Belron - vehicle glass repair company on track to speed up product approval processes by 75 per cent, available from www.microsoft.com/uk (accesied December 2004), (RatiOne).
37 Cadas, C. The KM spectrum deciding on a (local) KM strategy, What KM to do (first). The Strategic Knowledge Management Forum, London, Osney Media, 2005.

38 Winkler, B. Business process driven knowledge management. The Strategic Knowledge Management Forum, London, Osney Media, 2005.

39 Lovett, P. J. and Bancroft, C. N. Knowledge-based engineering for SMEs - a methodology. J. Mater. Process. Technol., 2000, 107, 384-389.

40 Kornfein, M. Architecture for process knowledge capture and deployment by domain experts. Intell. Syst. in Accounting, Finance, Mgmt, 2003, 11(4), 269-276.

41 Nokia. WISE (Web enabled, Information, Service and Engineering). KM for Engineering Day, Brussels, 21 June 2002.

42 Scarborough, P. H. Limits of (some) knowledge management. The Strategic Knowledge Management Forum, London, Osney Media, 2005.

43 Walters, G. E. (Fulcrum Pharma Developments) Managing knowledge transfer and sharing with outsourced service providers in pharmaceutical development. The Strategic Knowledge Management Forum, London, Osney Media, 2005.

44 Dwivedi, S. N. Development of knowledge-based engineering module for diagnosis of defects in casting and interpretation of defects by non-destructive testing. J. Mater. Process. Technol., 2003, 141, 155-162.

45 Chapman, C. B. Design engineering - a need to rethink the solution using knowledge-based engineering. Knowledge-based Systems, 1999, 12, 257-267.

46 Alderman, N., Ivory, C. J., Thwaites, A., and Vaugan, R. Knowledge management for projects integration: case studies of capital investment programmes. Presented at Managing Knowledge: Conversations and Critiques Conference, University of Leicester, 10-11 April 2001.

47 Bridge, D. D. Knowledge-based thermal analysis spreadsheet. MIRA - New Technology, 2003.

48 Davenport, T. H. Working knowledge - how organisations manage what they know, 1998 (Harvard Business School Press).

49 Schafer-Jugel, A. Case study: initiating knowledge sharing and re-using knowledge at Eli Lilly Critical Care Europe. The Strategic Knowledge Management Forum, London, Osney Media, 2005. 